\title{
Undifferentiated-type gastric adenocarcinoma: prognostic impact of three histological types
}

\author{
Han Hong Lee ${ }^{12^{*}}$, Kyo Young Song ${ }^{1}$, Cho Hyun Park ${ }^{1}$ and Hae Myung Jeon ${ }^{1}$
}

\begin{abstract}
Background: The prognostic value of the three constituents of undifferentiated-type gastric adenocarcinoma remains unclear. The present study assessed the clinicopathological characteristics and prognosis of undifferentiated-type mucinous adenocarcinoma (UMAC) and signet ring cell carcinoma (SRC) compared with those of poorly differentiated adenocarcinoma (PDAC).

Methods: In total, 1,376 patients with undifferentiated-type gastric adenocarcinoma were included, consisting of 1,002 patients diagnosed with PDAC, 54 with UMAC and 320 with SRC. Clinicopathological factors and survival rates were compared among the three histological types.

Results: Significant differences in the distribution of pathological stages were observed among the groups. Patients with SRC had a significantly better survival rate than those with PDAC or UMAC, in both the all patients including non-curative resected patients and curative-resected groups. In addition, there was significant difference in survival between the PDAC and UMAC groups. Multivariate analysis suggested that age, gender, tumor depth, lymph node metastasis and curability significantly affected survival. Histological type was not an independent prognostic factor. There was no significant difference in the pattern of recurrence among the three groups.

Conclusions: The UMAC and SRC had worse and favorable prognosis compared with PDCA, respectively. However, there were no differences in survival by pathological stage, thus histological type was not an independent predictor of prognosis.
\end{abstract}

Keywords: Mucinous adenocarcinoma, Signet ring cell carcinoma, Stomach neoplasms, Tubular adenocarcinoma

\section{Background}

According to the World Health Organization (WHO) classification, the four predominant histological types of gastric adenocarcinoma are tubular adenocarcinoma, papillary adenocarcinoma, mucinous adenocarcinoma (MAC) and signet ring cell carcinoma (SRC) [1]. Unlike tubular adenocarcinoma, which is graded as well-, moderately- or poorly-differentiated according to the degree of glandular formation, papillary adenocarcinoma is usually classified as well-differentiated, and SRC as poorly-differentiated. The Japanese classification system categorizes gastric adenocarcinomas into two groups: differentiated and undifferentiated. The differentiated group consists of

\footnotetext{
*Correspondence: painkiller9@catholic.ac.kr
'Division of Gastrointestinal Surgery, Department of Surgery, College of

* Correspondence: painkiller9@catholic.ac.kr
'Division of Gastrointestinal Surgery, Department of Surgery, College of Medicine, The Catholic University of Korea, Seoul, South Korea

${ }^{2}$ Department of Surgery, Uijeongbu St. Mary's Hospital, College of Medicine, The Catholic University of Korea, 65-1 Gumo-Dong, Uijeongbu-City, Gyenggi-Do 480-717, South Korea
}

(c) 2012 Lee et al.; licensee BioMed Central Ltd. This is an Open Access article distributed under the terms of the Creative Commons Attribution License (http://creativecommons.org/licenses/by/2.0), which permits unrestricted use, distribution, and reproduction in any medium, provided the original work is properly cited. well-differentiated, moderately-differentiated and papillary poorly differentiated adenocarcinoma (PDAC) and SRC. Interestingly, MAC can be regarded as either a differentiated or undifferentiated type depending on the predominant components [2]. In the same context, Nakamura categorized all gastric cancer as either differentiated or undifferentiated $[3,4]$.

Undifferentiated-type gastric adenocarcinomas in general have a worse prognosis. The innate characteristics and prognosis of MAC and SRC have been studied [5-18]. However, the results of those studies are still debated. Although MAC definitely has a dismal prognosis, several studies have reported that this is due to its typically advanced stage at diagnosis, rather than its cellular nature [17-20]. In addition, the clinicopathological features of SRC remain unclear. Some studies reported that early-stage gastric SRC was associated with a better 
prognosis than non-SRC, but in advanced gastric cancer, SRC histology was not an independent prognostic factor [6-9]. Others insisted that SRC had a prognosis similar to non-SRC $[13,14]$, or that SRC was an independent predictor of a poor prognosis [15]. However, most studies have compared one type, such as MAC or SRC, with all other types of gastric cancer. Our hypothesis was that a comparison limited to only undifferentiated types would provide a more practical analysis. Moreover, an appropriate standard of comparison is required to clarify the oncologic significance of these cell types. Therefore, in this study, we set PDAC as the comparison object in order to determine the characteristics of particular histologies, such as MAC and SRC.

\section{Methods}

\section{Definition}

In accordance with the WHO [1] and the Japanese Gastric Cancer Association (JGCA) [2], we defined PDAC as tubular adenocarcinoma composed of highly irregular glands that are recognized with difficulty, or single cells that remain isolated or are arranged in small or large clusters. MAC and SRC were defined as tumors in which more than $50 \%$ of the tumor area contained extracellular mucin pools and tumors consisting of isolated or small groups of malignant cells containing intracytoplasmic mucin, respectively.

\section{Patients}

Between 1989 and 2005, a total of 2,709 patients diagnosed with gastric cancer underwent surgery at Seoul St. Mary's Hospital. All of the surgical procedures were performed by three experienced gastric surgeons of our single institution with a definitive treatment guideline for gastric cancer. An eligibility criterion was patients who underwent gastrectomy accompanied by lymph node dissection with a primary gastric adenocarcinoma. Patients with synchronous malignancies or remnant gastric cancer and those who were diagnosed as differentiated-type adenocarcinoma (papillary adenocarcinoma, well and moderately tubular adenocarcinma, and differentiatedtype MAC) were excluded from the present study. Finally, 1,002 patients histologically diagnosed as PDAC, 54 diagnosed as undifferentiated-type MAC (uMAC), and 320 diagnosed as SRC were enrolled in the study. Clinicopathological parameters, including gender and age of patients; number, size and location of tumors; depth of invasion; lymph node metastasis status; lymphovascular and perineural invasion; and operative details, were collected retrospectively from the Gastric Cancer Patients Registry of Seoul St. Mary's Hospital. Cancer staging was as described in the seventh edition of the International Union Against Cancer TNM classification [21].
Regular follow-up programs were conducted; these involved the determination of tumor marker levels, abdominal computed tomography (CT) and endoscopic examination, according to our standard protocol (every 3 and 6 months for advanced and early gastric cancer, respectively, for the first 3 years; and every 12 months thereafter). The mean follow-up period of the enrolled patients was $92.3 \pm 68.7$ months (range, 0.3 to 267.4 months; $n=1,425)$. Survival rates were repeatedly determined using the registration data of the Korea National Statistical Office (KNSO) and medical records.

Written informed consent was obtained from the patient for publication of this report and any accompanying images. This study was approved by the institutional review board of the ethical committee of the College of Medicine, Catholic University of Korea (KC11RISI0686).

\section{Statistical analysis}

Differences between groups were analyzed using the $t$-test for continuous variables and the $\chi^{2}$ test or Fisher's exact test for proportions. Survival analysis was performed using Kaplan-Meier methods with a log-rank test for univariate analysis, and multivariate analysis for survival was performed using a Cox proportional hazards model with the 'Backward LR' method. Statistical analyses were performed with SPSS version 13.0 (SPSS, Inc., Chicago, IL, USA), and $P$-values $<0.05$ were taken to indicate statistical significance.

\section{Results}

There were no significant differences in surgical procedure, including fulfillment of curative resection, between patients diagnosed with the three histological types (Table 1). In terms of clinicopathological characteristics, uMAC patients were significantly older and had tumors of larger diameter. A diffuse type of Lauren's classification was most common in SRC patients and intestinal type was not observed. Lymphatic and perineural invasion were significantly lower in SRC than in the other types and vascular invasion was higher in uMAC. In contrast to uMAC tumors, which were present at an advanced stage with deeper invasion and more lymph node involvement, SRC was typically detected at an earlier stage. PDAC tumors tended to be detected at stages between those of uMAC and SRC (Table 2).

There was a significant difference in overall five-year survival between patients with SRC (77.4\%) and those with PDAC $(64.0 \%, P<0.001)$ or uMAC $(48.1 \%, P<0.001)$. The five-year survival rates also differed significantly between patients with PDAC and uMAC $(P=0.024)$ (Figure 1). Of the 1,212 patients who underwent curative resection, the overall five-year survival of patients with SRC (84.8\%) was significantly higher than that of 
Table 1 Operative findings

\begin{tabular}{|c|c|c|c|c|}
\hline \multirow[t]{2}{*}{ Variable } & \multirow{2}{*}{$\frac{\text { PDAC }}{n=1002}$} & \multirow{2}{*}{$\frac{\text { uMAC }}{n=54}$} & \multirow{2}{*}{$\frac{\text { SRC }}{n=320}$} & \multirow[t]{2}{*}{$P$-value } \\
\hline & & & & \\
\hline \multicolumn{5}{|c|}{ Extent of resection, n (\%) } \\
\hline Subtotal & $683(68.2)$ & $38(70.4)$ & $230(71.9)$ & \multirow[t]{2}{*}{0.448} \\
\hline Total & $319(31.8)$ & $16(29.6)$ & $90(28.1)$ & \\
\hline \multicolumn{5}{|c|}{ Lymph node dissection, n (\%) } \\
\hline D1 & $66(6.6)$ & $6(11.1)$ & $23(7.2)$ & \multirow[t]{3}{*}{0.167} \\
\hline $\mathrm{D} 1+$ & $54(5.4)$ & $1(1.9)$ & $26(8.1)$ & \\
\hline More than D2 & $882(88.0)$ & $47(87.0)$ & $271(84.7)$ & \\
\hline \multicolumn{5}{|c|}{ Reconstruction, n (\%) } \\
\hline Billroth-I & $95(9.5)$ & $5(9.3)$ & $44(13.8)$ & \multirow[t]{3}{*}{0.240} \\
\hline Billroth-II & $588(58.7)$ & $31(57.4)$ & $186(58.1)$ & \\
\hline Roux-en-Y & $319(31.8)$ & $18(33.3)$ & $90(28.1)$ & \\
\hline \multicolumn{5}{|c|}{ Combined resection, n (\%) } \\
\hline Present & $123(12.3)$ & $8(14.8)$ & $31(9.7)$ & \multirow[t]{2}{*}{0.356} \\
\hline Absent & $879(87.7)$ & $46(85.2)$ & $289(90.3)$ & \\
\hline \multicolumn{5}{|l|}{ Curability, n (\%) } \\
\hline Curative & $876(87.4)$ & $45(83.3)$ & $291(90.9)$ & \multirow[t]{2}{*}{0.132} \\
\hline Non-curative & $126(12.6)$ & $9(16.7)$ & $29(9.1)$ & \\
\hline
\end{tabular}

patients with PDAC (71.9\%; $P<0.001)$ or uMAC $(57.8 \%$; $P<0.001)$, and there was significant difference in fiveyear survival between PDAC and uMAC $(P=0.039)$ (Figure 2).

In a comparison of five-year survival rates in the three histological groups by pathological stage, there were no significant differences among either all or curatively resected patients (Table 3 ). In addition, no significant difference in the five-year survival rates was detected among any pathological $\mathrm{T} / \mathrm{N}$-stage (data not shown).

Multivariate analysis using a Cox proportional hazard regression model showed that older age, male gender, depth of invasion, lymph node metastasis and curability were independently associated with a poor prognosis (Table 4). Among patients who had undergone curative resection, older age, tumor diameter, depth of invasion and lymph node metastasis were identified as independent prognostic factors (Table 5). Histological type was not an independent prognostic factor in either group.

Of the 1,212 patients who underwent curative resection, 290 (23.9\%) experienced a recurrence. There was a significant difference among the three groups $(P<0.001)$, with UMAC and SRC patients having the highest and lowest recurrence rates, respectively. However, there was no significant difference in recurrence rates among the groups according to pathological stage (stage I, $P=$ 0.626 ; stage II, $P=530$; stage III, $P=0.574$ ). In addition, there were no significant differences in the pattern of recurrence $(P=0.819)$ (Table 6$)$.

\section{Discussion}

Undifferentiated types of gastric adenocarcinoma are correlated with aggressive neoplasms associated with more extensive and infiltrative growth, lymph node metastasis and distant metastasis characterized by peritoneal dissemination and, therefore, have a worse prognosis than differentiated types [22,23]. Prognosis for three gastric adenocarcinomas, such as SRC, PDAC and uMAC, which belong to the undifferentiated type, is still not established and there were few studies to deal with only undifferentiated-type gastric adenocarcinomas. For the design of this study, MAC was sub-classified into differentiated-type MAC and uMAC. By our results, SRC and uMAC had the best and worst prognosis, respectively, in a univariate analysis of overall survival. The same trend in survival differences was observed in curatively resected patients. Such a result for uMAC agreed with the previous reports stating that MAC had a dismal prognosis [16-20].

In contrast to MAC, which has shown consistent results, data regarding the prognosis of SRC are conflicting, although most studies did not take into account the differentiation category. Only one report by Fang et al. [5] compared SRC and MAC, both of which are mucin-producing gastric cancers. They reported that patients with SRC had better five-year survival than those with MAC in stages I and II gastric cancer, but there was no difference in five-year survival in advancedstage cancer. However, histological type was not an 
Table 2 Clinicopathological characteristics

\begin{tabular}{|c|c|c|c|c|}
\hline \multirow[t]{2}{*}{ Variable } & \multirow{2}{*}{$\begin{array}{c}\text { PDAC } \\
n=1002\end{array}$} & \multirow{2}{*}{$\begin{array}{l}\text { uMAC } \\
n=54\end{array}$} & \multirow{2}{*}{$\begin{array}{c}\text { SRC } \\
n=320\end{array}$} & \multirow[t]{2}{*}{$P$-value } \\
\hline & & & & \\
\hline Age, years (mean $\pm S D$ ) & $54.6 \pm 12.8$ & $57.3 \pm 12.1$ & $52.4 \pm 12.0$ & 0.003 \\
\hline \multicolumn{5}{|l|}{ Gender, n (\%) } \\
\hline Male & $605(60.4)$ & $35(64.8)$ & $187(58.4)$ & \multirow[t]{2}{*}{0.637} \\
\hline Female & $397(39.6)$ & 19 (35.2) & $133(41.6)$ & \\
\hline \multicolumn{5}{|l|}{ Multiplicity, n (\%) } \\
\hline Single & $982(98.0)$ & $53(98.1)$ & $316(98.8)$ & \multirow[t]{2}{*}{0.612} \\
\hline Multiple & $20(2.0)$ & $1(1.9)$ & $4(1.3)$ & \\
\hline \multicolumn{5}{|l|}{ Tumor location, n (\%) } \\
\hline Upper & $108(10.8)$ & $4(7.4)$ & $22(6.9)$ & \multirow[t]{4}{*}{0.184} \\
\hline Middle & $392(39.1)$ & $17(31.5)$ & $141(44.1)$ & \\
\hline Lower & $452(45.1)$ & $31(57.4)$ & 139 (43.4) & \\
\hline Whole & $50(5.0)$ & $2(3.7 \%)$ & $18(5.6)$ & \\
\hline Tumor size, cm (mean \pm SD) & $5.7 \pm 3.7$ & $7.1 \pm 3.8$ & $4.8 \pm 3.2$ & $<0.001$ \\
\hline \multicolumn{5}{|l|}{ Lauren, n (\%) } \\
\hline Intestinal type & $0(0)$ & $0(0)$ & $0(0)$ & \multirow[t]{3}{*}{$<0.001$} \\
\hline Diffuse type & $782(78.0)$ & $37(68.5)$ & $290(90.6)$ & \\
\hline Mixed type & $220(22.0)$ & $17(31.5)$ & $30(9.4)$ & \\
\hline \multicolumn{5}{|l|}{ Lymphatic invasion, n (\%) } \\
\hline Present & $607(60.6)$ & $42(77.8)$ & $120(37.5)$ & \multirow[t]{2}{*}{$<0.001$} \\
\hline Absent & $395(39.4)$ & $12(22.2)$ & $200(62.5)$ & \\
\hline \multicolumn{5}{|l|}{ Vascular invasion, n (\%) } \\
\hline Present & $105(10.5)$ & $12(22.2)$ & $27(8.4)$ & \multirow[t]{2}{*}{0.009} \\
\hline Absent & $897(89.5)$ & $42(77.8)$ & 293 (91.6) & \\
\hline \multicolumn{5}{|l|}{ Perineural invasion, n (\%) } \\
\hline Present & $490(48.9)$ & $29(53.7)$ & $108(33.8)$ & \multirow[t]{2}{*}{$<0.001$} \\
\hline Absent & $512(51.1)$ & $25(46.3)$ & $212(66.3)$ & \\
\hline \multicolumn{5}{|l|}{ Depth of invasion, n (\%) } \\
\hline $\mathrm{T} 1$ & $248(24.8)$ & $3(5.6)$ & $164(51.3)$ & \multirow[t]{4}{*}{$<0.001$} \\
\hline $\mathrm{T} 2$ & $152(15.2)$ & $4(7.4)$ & $32(10.0)$ & \\
\hline T3 & $242(24.2)$ & $13(24.1)$ & $40(12.5)$ & \\
\hline T4 & $360(35.9)$ & $34(63.0)$ & $84(26.3)$ & \\
\hline \multicolumn{5}{|l|}{ Lymph node metastasis, n (\%) } \\
\hline No & $422(42.1)$ & $9(16.7)$ & $201(62.8)$ & \multirow[t]{4}{*}{$<0.001$} \\
\hline N1 & $134(13.4)$ & $11(20.4)$ & $25(7.8)$ & \\
\hline N2 & $131(13.1)$ & $10(18.5)$ & $27(8.4)$ & \\
\hline N3 & $315(31.4)$ & $24(44.4)$ & $67(20.9)$ & \\
\hline \multicolumn{5}{|l|}{ Pathological stage, n (\%) } \\
\hline । & $323(32.2)$ & $4(7.4)$ & $180(56.3)$ & \multirow[t]{4}{*}{$<0.001$} \\
\hline$\|$ & $212(21.2)$ & $11(20.4)$ & $50(15.6)$ & \\
\hline III & 354 (35.3) & 30 (55.6) & $64(20.2)$ & \\
\hline IV & $113(11.3)$ & $9(16.7)$ & $26(8.1)$ & \\
\hline
\end{tabular}




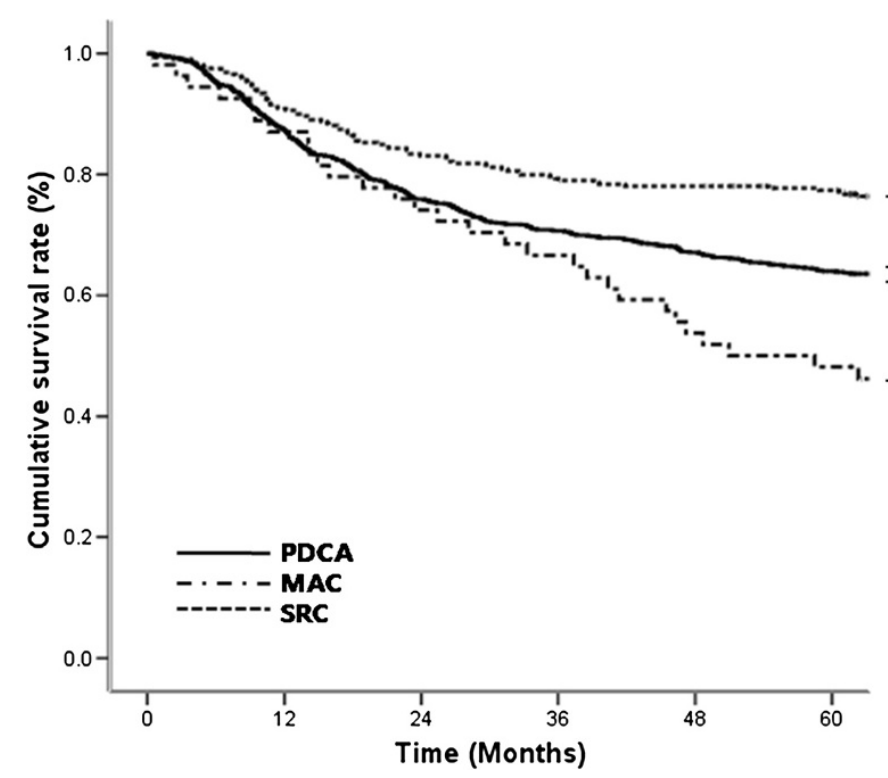

Figure 1 Survival curves of patients with mucinous adenocarcinoma (MAC), signet ring cell carcinoma (SRC), or poorly differentiated adenocarcinoma (PDAC).

independent prognostic factor in their multivariate analysis. In the present study, while there was a significantly better five-year survival rate of SRC in all enrolled patients, patients with SRC did not have a more favorable five-year survival than those with $\mathrm{UMAC}$ and PDAC according to pathological stage, and histological type was also not associated with prognosis. Thus, the higher proportion of early stage SRC led to its better prognosis. The uMAC also did not have a significantly worse fiveyear survival rate than the other two types in comparison with each pathological stage. Similarly, an advanced stage of UMAC at diagnosis can explain that cause. Therefore, follow-up and postoperative strategy, such as adjuvant chemotherapy for undifferentiated-type gastric adenocarcinoma, would be tailored based on each pathological stage, irrespective of histological type.

It is uncertain why SRC and MAC present an early and advanced stage at diagnosis, respectively. One possible explanation regarding SRC is that SRC tends to expand superficially to mucosal and submucosal layers.

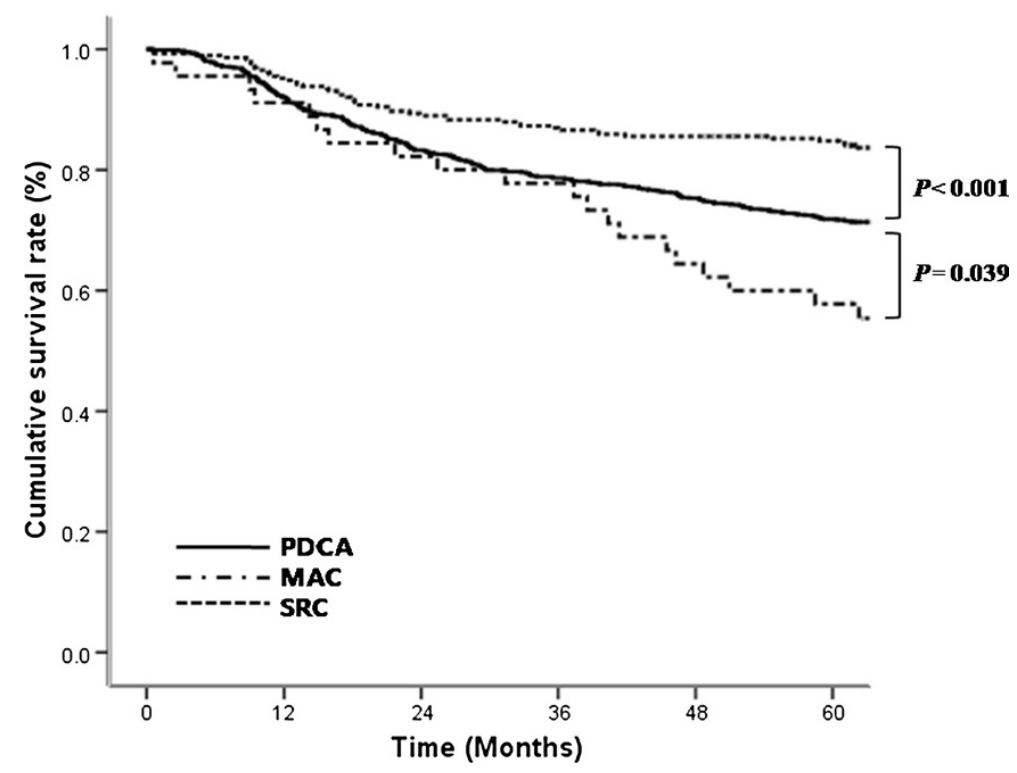

Figure 2 Survival curves for patients with MAC, SRC, or PDAC who underwent curative resection. 
Table 3 Comparison of five-year survival rates according to pathological stage

\begin{tabular}{ccccc}
\hline Stage & PDAC & uMAC & SRC & $P$-value \\
\hline \multirow{5}{*}{ I } & All, n (\%) & \\
II & 95.3 & 100.0 & 96.6 & 0.575 \\
III & 77.0 & 81.8 & 84.0 & 0.333 \\
IV & 45.9 & 43.3 & 49.2 & 0.791 \\
& 5.5 & 11.1 & 3.8 & 0.421 \\
& & & & \\
I & & Curative, n (\%) & \\
II & 77.6 & 100.0 & 96.6 & 0.575 \\
III & 48.3 & 81.8 & 84.0 & 0.369 \\
\hline
\end{tabular}

Then, the broad tumor causes the clinical symptoms, such as epigastric soreness, and can be detected at an early stage [24]. With regard to MAC, the role of extracellular mucin has been reported. Extracellular mucin of MAC acts as an infiltrating medium and promotes the dispersion and invasion of tumor cells to deeper layers $[10,25]$. In addition, mucin can inhibit the inflammatory and immunologic reactions of tumor cells [26].

Although it is known that undifferentiated-type gastric adenocarcinoma is associated with the diffuse type of Lauren classification, few studies have reported a correlation between histology type and Lauren classification.
The WHO defined the diffuse type as a histological form comprised of poorly cohesive cells with little or no gland formation [1], and this shape almost matched up with the SRC type. The present study, in which the proportion of the diffuse type was highest in SRC (90.6\%), followed by PDAC (78.0\%) and uMAC (68.5\%), reflected such an association. The intestinal type of undifferentiated-type gastric adenocarcinoma was very rare, and there was no case of the intestinal type in the present study. The structure of the intestinal type was partially observed at the advancing margin of undifferentiated-type gastric adenocarcinoma belonging to the mixed type.

In the present study, a Cox proportional hazard regression model identified older age, male gender, depth of invasion, lymph node metastasis and curability as independent prognostic factors in undifferentiated gastric adenocarcinomas. The N1 stage did not have prognostic significance, and the hazard ratio of the N2 stage was low. The current study was based on the seventh edition of the International Union Against Cancer TNM classification, which has a narrow division of $\mathrm{N} 1$ and N2 stages: $\mathrm{N} 1$ for one to two positive lymph nodes and $\mathrm{pN} 2$ for three to six. Our previous study [27] reported the low power of discrimination of the seventh edition $\mathrm{N}$ classification owing to this narrow range. The current $\mathrm{N}$ stage results in undifferentiated type cancers were also considered to be attributable to the seventh edition $\mathrm{N}$ classification.

Table 4 Multivariate analysis of prognostic factors for survival in all enrolled patients

\begin{tabular}{|c|c|c|c|c|}
\hline Variable & Coefficient & SE & Hazard ratio $(95 \% \mathrm{Cl})$ & $P$-value \\
\hline \multicolumn{5}{|l|}{ Age, years } \\
\hline$\geq 65 /<65$ & 0.546 & 0.093 & 1.727 (1.440 to 2.072$)$ & $<0.001$ \\
\hline \multicolumn{5}{|l|}{ Gender } \\
\hline Male/Female & 0.229 & 0.088 & 1.257 (1.057 to 1.495$)$ & 0.010 \\
\hline \multicolumn{5}{|l|}{ Tumor size, cm } \\
\hline$\geq 5 /<5$ & 0.152 & 0.111 & 1.164 (0.936 to 1.447$)$ & 0.171 \\
\hline \multicolumn{5}{|l|}{ Depth of invasion } \\
\hline $\mathrm{T} 2 / \mathrm{T} 1$ & 0.618 & 0.204 & 1.856 (1.245 to 2.766$)$ & 0.002 \\
\hline $\mathrm{T} 3 / \mathrm{T} 1$ & 0.856 & 0.188 & 2.353 (1.626 to 3.403$)$ & $<0.001$ \\
\hline $\mathrm{T} 4 / \mathrm{T} 1$ & 1.532 & 0.184 & 4.629 (3.227 to 6.641$)$ & $<0.001$ \\
\hline \multicolumn{5}{|l|}{ Lymph node metastasis } \\
\hline N1/N0 & 0.077 & 0.175 & 1.080 (0.766 to 1.523$)$ & 0.661 \\
\hline N2/N0 & 0.614 & 0.158 & 1.847 (1.356 to 2.516$)$ & $<0.001$ \\
\hline N3/N0 & 1.100 & 0.136 & 3.005 (2.301 to 3.925$)$ & $<0.001$ \\
\hline \multicolumn{5}{|l|}{ Curability } \\
\hline Non-curative/Curative & 1.104 & 0.110 & 3.016 (2.433 to 3.740$)$ & $<0.001$ \\
\hline \multicolumn{5}{|l|}{ Histology } \\
\hline PDAC/SRC & 0.071 & 0.114 & 1.074 (0.858 to 1.343$)$ & 0.534 \\
\hline UMAC/SRC & -0.018 & 0.205 & 0.982 (0.658 to 1.467$)$ & 0.930 \\
\hline
\end{tabular}


Table 5 Multivariate analysis of prognostic factors for survival in enrolled patients who underwent curative resection

\begin{tabular}{|c|c|c|c|c|}
\hline Variable & Coefficient & SE & Hazard ratio $(95 \% \mathrm{Cl})$ & $P$-value \\
\hline \multicolumn{5}{|l|}{ Age, years } \\
\hline$\geq 65 /<65$ & 0.667 & 0.108 & 1.949 (1.576 to 2.409$)$ & $<0.001$ \\
\hline \multicolumn{5}{|l|}{ Gender } \\
\hline Male/Female & 0.200 & 0.103 & 1.221 (0.998 to 1.494$)$ & 0.053 \\
\hline \multicolumn{5}{|l|}{ Tumor size, cm } \\
\hline$\geq 5 /<5$ & 0.237 & 0.118 & 1.268 (1.007 to 1.597$)$ & 0.043 \\
\hline \multicolumn{5}{|c|}{ Depth of invasion } \\
\hline $\mathrm{T} 2 / \mathrm{T} 1$ & 0.582 & 0.208 & 1.789 (1.190 to 2.689$)$ & 0.005 \\
\hline $\mathrm{T} 3 / \mathrm{T} 1$ & 0.749 & 0.196 & 2.114 (1.439 to 3.106$)$ & $<0.001$ \\
\hline $\mathrm{T} 4 / \mathrm{T} 1$ & 1.433 & 0.196 & 4.192 (2.855 to 6.155$)$ & $<0.001$ \\
\hline \multicolumn{5}{|c|}{ Lymph node metastasis } \\
\hline N1/N0 & 0.015 & 0.192 & 1.016 (0.696 to 1.481$)$ & 0.936 \\
\hline N2/N0 & 0.558 & 0.168 & 1.747 (1.256 to 2.428$)$ & 0.001 \\
\hline N3/N0 & 1.161 & 0.143 & 3.195 (2.414 to 4.228$)$ & $<0.001$ \\
\hline \multicolumn{5}{|l|}{ Histology } \\
\hline PDAC/SRC & 0.157 & 0.136 & 1.170 (0.896 to 1.528$)$ & 0.248 \\
\hline UMAC/SRC & 0.135 & 0.242 & 1.144 (0.712 to 1.840$)$ & 0.578 \\
\hline
\end{tabular}

This study has a limitation. The survival benefits of adjuvant chemotherapy were not clarified. Most patients diagnosed as having advanced stage received adjuvant chemotherapy, most commonly 5 -FU or cisplatin-based systemic chemotherapy, based on our institute's guidelines. However, this study lacked consistency regarding patient and drug selection because of the nature of very long-term data, especially for second-line chemotherapy.

\section{Conclusions}

Compared with patients with PDAC, the overall survival of patients with UMAC was significantly worse and those with SRC had a better prognosis. However, since there were no differences in five-year survival between histological type according to cancer stage and having no histological type was not an independent prognostic factor, treatment strategy would be focused on the stage of undifferentiated-type gastric adenocarcinoma at diagnosis.

Table 6 Recurrence rates and patterns

\begin{tabular}{|c|c|c|c|c|}
\hline \multirow[t]{2}{*}{ Variable } & \multirow{2}{*}{$\begin{array}{c}\text { PDAC } \\
n=876\end{array}$} & \multirow{2}{*}{$\begin{array}{l}\text { uMAC } \\
n=45\end{array}$} & \multirow{2}{*}{$\frac{\text { SRC }}{n=291}$} & \multirow[t]{2}{*}{$P$-value } \\
\hline & & & & \\
\hline Recurrence, n (\%) & $228(26.0)$ & $20(44.4)$ & $42(14.4)$ & $<0.001$ \\
\hline \multicolumn{5}{|l|}{ Pattern, n (\%) } \\
\hline Peritoneal & $100(43.9)$ & $7(35.0)$ & $15(35.7)$ & 0.819 \\
\hline Lymphatic & 34 (14.9) & $3(15.0)$ & $9(21.4)$ & \\
\hline Remnant stomach & $15(6.6)$ & $2(10.0)$ & $1(2.4)$ & \\
\hline Hematogenous & $37(16.2)$ & $4(20.0)$ & $9(21.4)$ & \\
\hline Combined & $42(18.4)$ & $4(20.0)$ & $8(19.0)$ & \\
\hline
\end{tabular}

\section{Abbreviations}

WHO: World health organization; MAC: Mucinous adenocarcinoma; SRC: Signet ring cell carcinoma; PDCA: Poorly differentiated adenocarcinoma; JGCA: Japanese gastric cancer association; UMAC: Undifferentiated-type mucinous adenocarcinoma; CT: Computed tomography; KNSO: Korea national statistical office.

\section{Competing interests}

The authors declare that they have no competing interests.

\section{Authors' contributions}

HHLcontributed to study conception and design, analysis of data, drafting of the manuscript and critical revision. KYS was responsible for acquisition and interpretation of data. CHP was responsible for interpretation of data and critical revision. HMJ contributed to study conception and design and critical revision. All authors read and approved the final manuscript.

Received: 9 May 2012 Accepted: 15 October 2012

Published: 26 November 2012

\section{References}

1. Watanabe H, Jass JR, Sobin LH: Histological typing of esophageal and gastric tumors: WHO international histological classification of tumors. 2nd edition. Berlin: Springer; 1990.

2. Japanese Gastric Cancer Association: Japanese classification of gastric carcinoma - 2nd English edition. Gastric Cancer 1998, 1:10-24.

3. Nakamura K, Sugano H, Takagi K: Carcinoma of the stomach in incipient phase: its histogenesis and histological appearances. Gann 1968, 59:251-258

4. Sugano H, Nakamura K, Kato Y: Pathological studies of human gastric cancer. Acta Pathol Jpn 1982, 32(Suppl 2):329-347.

5. Fang $W L$, Wu CW, Lo SS, Chen JH, Hsieh MC, Shen KH, Li AF, Tai LC, Lui WY: Mucin-producing gastric cancer: clinicopathological difference between signet ring cell carcinoma and mucinous carcinoma. Hepatogastroenterology 2009, 56:1227-1231.

6. Chiu CT, Kuo CJ, Yeh TS, Hsu JT, Liu KH, Yeh CN, Hwang TL, Jan YY, Lin CJ: Early signet ring cell gastric cancer. Dig Dis Sci 2011, 56:1749-1756.

7. Jiang CG, Wang ZN, Sun Z, Liu FN, Yu M, Xu HM: Clinicopathologic characteristics and prognosis of signet ring cell carcinoma of the stomach: results from a Chinese mono-institutional study. J Surg Oncol 2011, 103:700-703. 
8. Kunisaki C, Shimada H, Nomura M, Matsuda G, Otsuka Y, Akiyama H: Therapeutic strategy for signet ring cell carcinoma of the stomach. Br J Surg 2004, 91:1319-1324.

9. Otsuji E, Yamaguchi T, Sawai K, Takahashi T: Characterization of signet ring cell carcinoma of the stomach. J Surg Oncol 1998, 67:216-220.

10. Choi JS, Kim MA, Lee HE, Lee HS, Kim WH: Mucinous gastric carcinomas: clinicopathologic and molecular analyses. Cancer 2009, 115:3581-3590.

11. Hidaka S, Tanaka K, Takeshita H, Sumida Y, Fukuoka H, Abo T, Yano H, Nanashima A, Sawai T, Yasutake T, Nagayasu T: Clinicopathology and prognosis of mucinous gastric carcinoma. Hepatogastroenterology 2008, 55:791-794.

12. Kawamura H, Kondo Y, Osawa S, Nisida Y, Okada K, Isizu H, Uebayasi T, Takahasi M, Hata T: A clinicopathologic study of mucinous adenocarcinoma of the stomach. Gastric Cancer 2001, 4:83-86.

13. Kim DY, Park YK, Joo JK, Ryu SY, Kim YJ, Kim SK, Lee JH: Clinicopathological characteristics of signet ring cell carcinoma of the stomach. ANZ J Surg 2004, 74:1060-1064.

14. Zhang M, Zhu G, Zhang H, Gao H, Xue Y: Clinicopathologic features of gastric carcinoma with signet ring cell histology. J Gastrointest Surg 2010, 14:601-606.

15. Piessen $G$, Messager $M$, Leteurtre $E$, Jean-Pierre $T$, Mariette $C$ : Signet ring cell histology is an independent predictor of poor prognosis in gastric adenocarcinoma regardless of tumoral clinical presentation. Ann Surg 2009, 250:878-887.

16. Woo LS, Kim DY, Kim YJ, Kim SK: Clinicopathologic features of mucinous gastric carcinoma. Dig Surg 2002, 19:286-290.

17. Kunisaki C, Akiyama H, Nomura M, Matsuda G, Otsuka Y, Ono HA, Shimada $\mathrm{H}$ : Clinicopathologic characteristics and surgical outcomes of mucinous gastric carcinoma. Ann Surg Oncol 2006, 13:836-842.

18. Zhang M, Zhu GY, Zhang HF, Gao HY, Han XF, Xue YW: Clinicopathologic characteristics and prognosis of mucinous gastric carcinoma. J Surg Oncol 2010, 102:64-67.

19. Adachi Y, Yasuda K, Inomata M, Shiraishi N, Kitano S, Sugimachi K: Clinicopathologic study of early-stage mucinous gastric carcinoma. Cancer 2001, 91:698-703.

20. Yasuda K, Adachi Y, Shiraishi N, Yamaguchi K, Shiromizu A, Kitano S: Pathology and prognosis of mucinous gastric carcinoma. J Surg Oncol 2001, 76:272-277.

21. Edge SB, Byrd DR, Compton CC, Fritz AG, Greene FL, Trotti A: American joint committee on cancer (AJCC) cancer staging manual. 7th edition. New York: Springer; 2010.

22. Moriguchi S, Kamakura T, Odaka T, Nose Y, Maehara Y, Korenaga D, Sugimachi $\mathrm{K}$ : Clinical features of the differentiated and undifferentiated types of advanced gastric carcinoma: univariate and multivariate analyses. J Surg Oncol 1991, 48:202-206

23. Adachi Y, Yasuda K, Inomata M, Sato K, Shiraishi N, Kitano S: Pathology and prognosis of gastric carcinoma: well versus poorly differentiated type. Cancer 2000, 89:1418-1424.

24. Sugihara H, Hattori T, Fukuda M, Fujita S: Cell proliferation and differentiation in intramucosal and advanced signet ring cell carcinomas of the human stomach. Virchows Arch A Pathol Anat Histopathol 1987, 411:117-127.

25. Perez RO, Bresciani BH, Bresciani C, Proscurshim I, Kiss D, Gama-Rodrigues J, Pereira DD, Rawet V, Cecconnello I, Habr-Gama A: Mucinous colorectal adenocarcinoma: influence of mucin expression (Muc1, 2 and 5) on clinico-pathological features and prognosis. Int J Colorectal Dis 2008, 23:757-765.

26. Papadopoulos VN, Michalopoulos A, Netta S, Basdanis G, Paramythiotis D, Zatagias A, Berovalis P, Harlaftis N: Prognostic significance of mucinous component in colorectal carcinoma. Tech Coloproctol 2004, 8(Suppl 1): s123-125.

27. Jung $\mathrm{H}$, Lee HH, Song KY, Jeon HM, Park CH: Validation of the seventh edition of the american joint committee on cancer TNM staging system for gastric cancer. Cancer 2011, 117:2371-2378.

doi:10.1186/1477-7819-10-254

Cite this article as: Lee et al:: Undifferentiated-type gastric adenocarcinoma: prognostic impact of three histological types. World Journal of Surgical Oncology 2012 10:254.

\section{Submit your next manuscript to BioMed Central and take full advantage of:}

- Convenient online submission

- Thorough peer review

- No space constraints or color figure charges

- Immediate publication on acceptance

- Inclusion in PubMed, CAS, Scopus and Google Scholar

- Research which is freely available for redistribution 